$\underline{\text { Review }}$

\title{
What are the known effects of yoga on the brain in relation to motor performances, body awareness and pain? A narrative review
}

Emmanuelle Rivest-Gadbois ${ }^{\mathrm{a},}$

Marie-Hélène Boudriasa, b, c, *

mh.boudrias@mcgill.ca

aschool of Physical and Occupational Therapy, McGill University, Montreal, Quebec, Canada

${ }^{\mathbf{b}}$ Montreal Center for Interdisciplinary Research in Rehabilitation (CRIR), Montreal, Quebec, Canada

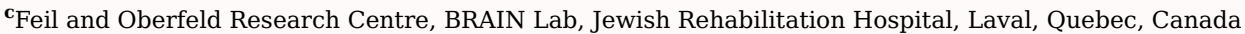

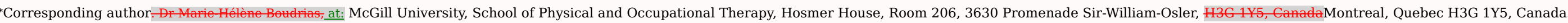

\section{Abstract}

Objective

The current body of literature was reviewed to evaluate the effects of yoga on the brain in relation to motor performance, body awareness and pain

Background

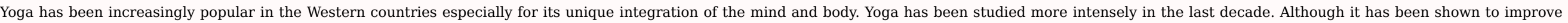
cognitive functions, few studies have looked into the effects of yoga on improving motor performance, body awareness or pain and the possible underlying brain mechanisms associated with them.

Methods

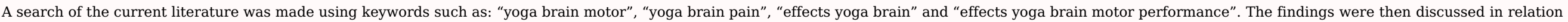
to motor performance, body awareness and pain and their reported mechanisms of action on the brain.

Results

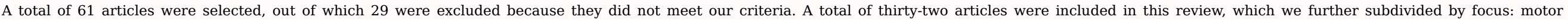
performance ( $\# \underline{\underline{n}}=10)$, body awareness $(\eta=14)$ a

\section{Discussio}

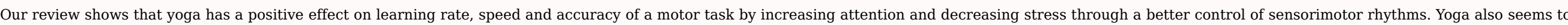

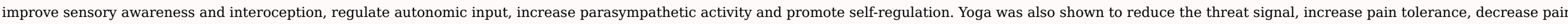
unpleasantness and decrease the anxiety and distress associated with pain. Those changes are associated with the recruitment of specific brain areas such as the insula, the amygdala and the hippocampus. Conclusion

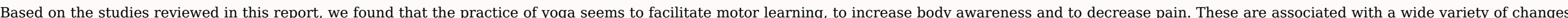
in terms of brain activity and structure. Further studies are necessary to reveal its precise mechanism of action on the brain and to validate its wider application in clinical settings.

Keywords: Yoga; Pain; Brain; Motor performance; Body awareness; Narrative review; Neuroimaging

\section{Introduction}

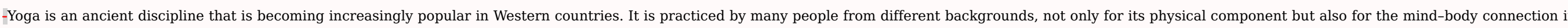




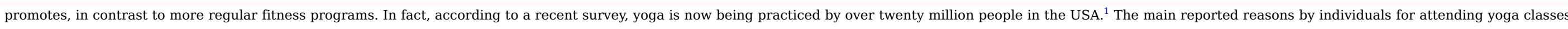

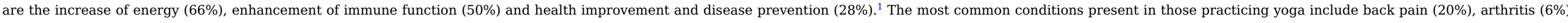
and stress $(6 \%){ }^{2}$ Consequently, yoga is increasingly considered as an affordable and promising modality for the management and the alleviation of the cost associated with these conditions. ${ }^{3}$

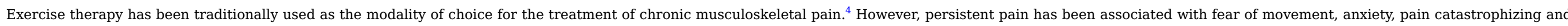

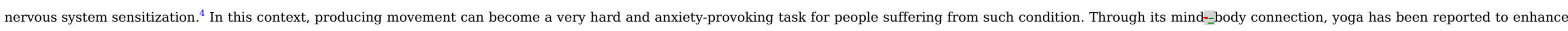

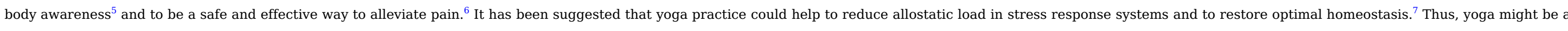

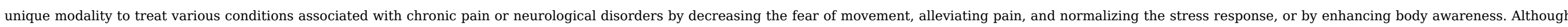

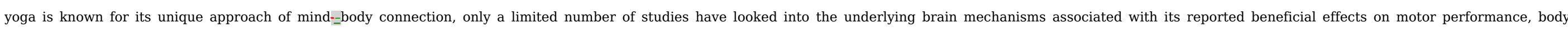

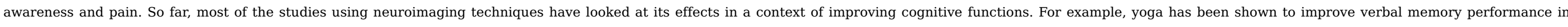

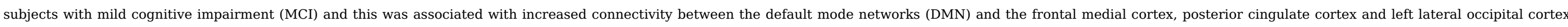
(Eyre, 2016). In this context, the purpose of this review was to identify the current existing literature on the effects of yoga on brain markers in relation to body awareness, motor performance and pain.

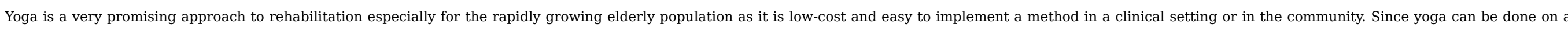

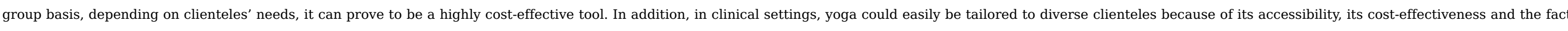

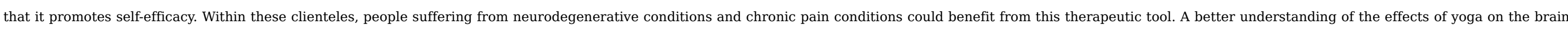
will help validate its use as a therapeutic tool in clinical settings, including its use on patients suffering from various neurodegenerative conditions.

\section{Method}

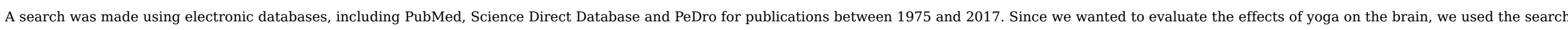

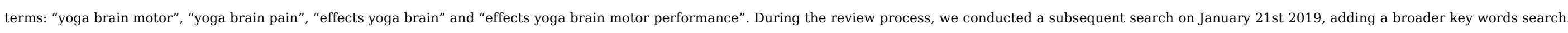
The key word "yoga + cortical activity", "yoga + cortex", "yoga + cortex + sensory", "yoga + cortex + sensorimotor", "yoga + cortex + somatosensory", "yoga + cortex" were then added to the search.

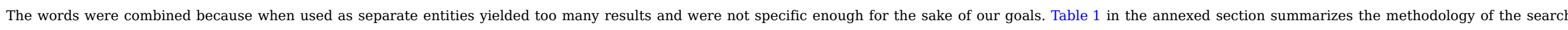

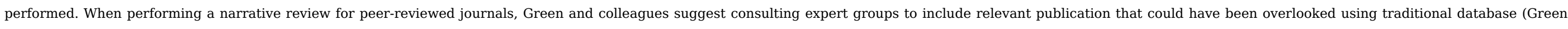

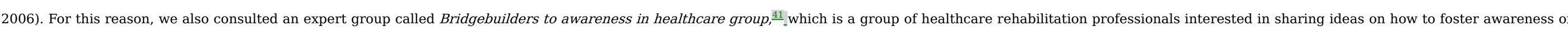

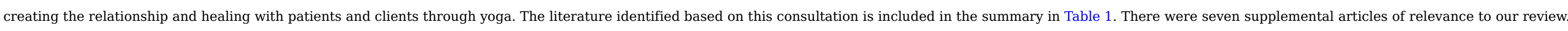

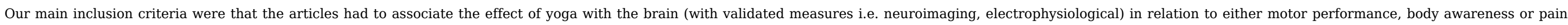

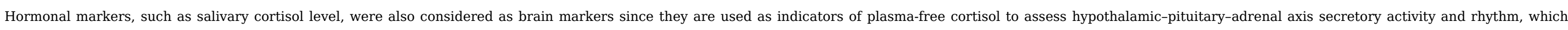
involve the stimulation of the adrenal cortex to produce cortisol.

Table 1 Literature search tracking sheet.

\begin{tabular}{|c|c|c|c|c|}
\hline Date of search & Database & years searehedsyears searched & $\underline{\text { Search terms }}$ & \# hits \\
\hline 02/11/2017 & PubMed & 1975--2017 & yoga brain motor & 12 \\
\hline 02/11/2017 & PubMed & 1975--2017 & yoga brain pain & 21 \\
\hline 02/11/2017 & PubMed & $1975-=2017$ & effects yoga brain & 77 \\
\hline 02/11/2017 & Science direct & Journal only & effects yoga brain motor performance & 339 \\
\hline 02/11/2017 & PeDro & Full database (1929-_2017) & effects yoga brain & 3 \\
\hline 02/23/2017 & PubMed & 1975-=2017 & Yoga AND brain (Pain OR body awareness OR motor performance) & 33 \\
\hline
\end{tabular}




\section{$02 / 12 / 2017$}

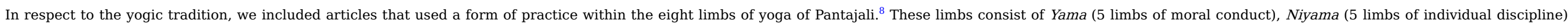

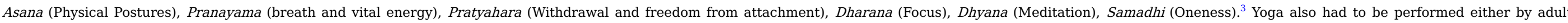

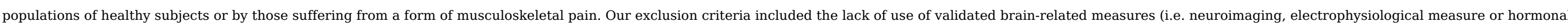

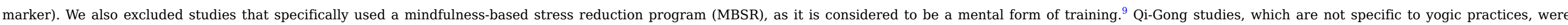

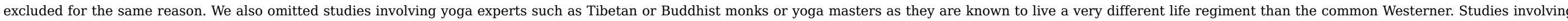

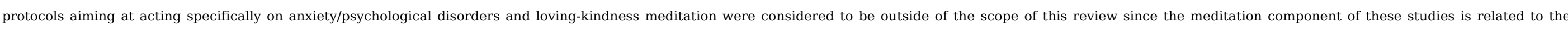

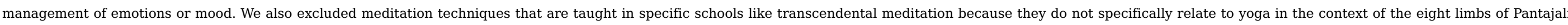

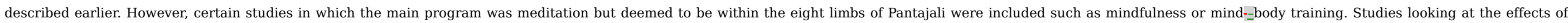
yoga on cognitive declines or impairments were also considered to be outside the scope of this review.

\section{Results}

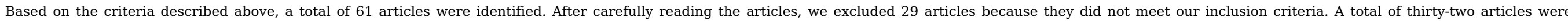

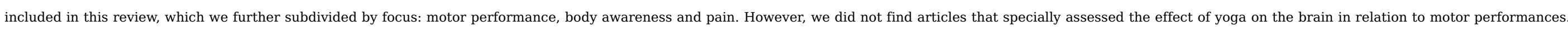

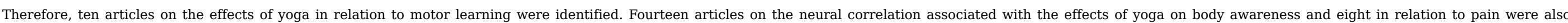
identified. A synthesis of the articles included in this review is provided in Table 2.

Table 2 Results from the effects of yoga on the brain in relation to motor learning/performance.

alt-text: Table 2

\begin{tabular}{|c|c|c|c|c|c|}
\hline Reference & Sample & Method & Mesures & Results & Comments \\
\hline $\begin{array}{l}\text { 10NCassady et } \\
\text { al. } . \underline{-}\end{array}$ & $\begin{array}{l}\frac{N}{N}=36 \text { healthy subjects }(22-35 \text { y.o.) } \\
\text { MBAT: } 12 \text { (min } 1-35 \text { y.o.) } \\
2 \text { MBAT: } 12 \text { (min } 1 \text { yr exp, } \\
\text { - CON: } 24 \text { subjects with little or no } \\
\text { exp. }(<10 \text { sessions) } \\
\text { All BCI naive } \text { - } 1 \text { ll BCI naive }\end{array}$ & $\begin{array}{l}\text { Investigate the role of prior } \\
\text { experience with MBAT, in learning } \\
\text { to use a 1-D sensorimotor rhythm } \\
\text { based BCI }\end{array}$ & $\begin{array}{l}\text { - EEG (Autoregressive spectral } \\
\text { amplitudes at } 12 \mathrm{~Hz} \text { ) } \\
-3 \text { BCI sessions of } 10 \text { min- for } 80 \% \\
\text { accuracy over Left-right } \& \text { up-down } \\
\text { cursor task } \\
\text { - PVC, \# of hits/run, ITR in bits/min }\end{array}$ & $\begin{array}{l}\text { 1-Left vs. right cursor task: MBAT } \\
\text { faster than CON } \\
\text { - MBAT higher accuracies of control vs } \\
\text { CON } \\
\text { - MBAT more hits/run vs CON } \\
\text { - MBAT higher ITRs vs CON } \\
\text { - Both left vs. right and overall 1D } \\
\text { control, the group-weighted average } \\
\text { neural power greater for MBAT vs } \\
\text { CON } \\
\text { - MBAT ability to learn at greater rate } \\
\text { than CON }\end{array}$ & $\begin{array}{l}\text { - Applied learning process to a new task } \\
\text { using an SMR-based BCI (controlled by } \\
\text { user's intention without external stimuli) } \\
\text { a motor imagery based BCI system }\end{array}$ \\
\hline $\begin{array}{l}\text { 11NChandra et } \\
\text { al. } 11\end{array}$ & $\begin{array}{l}N=25 \text { healthy subjects } \\
(30-=50 \text { y.o. }) \\
\text { SKY }=15 \\
\text { CON }=10_{-} \text {(both naive to yoga) } \\
\text { SKY underwent } 7 \text { days training in }\end{array}$ & $\begin{array}{l}\text { - Effects of SKY on brain signals } \\
\text { during Working memory task } \\
\text { - Working memory task }=20-25 \mathrm{~min} \\
\text { AOSPAN-25 min AOSPAN }\end{array}$ & $\begin{array}{l}\text { EEG (only gamma }(30-45 \mathrm{~Hz}) \text {, alpha } \\
(8-13 \mathrm{~Hz}) \text {, and theta }(4-8 \mathrm{~Hz}) \text { bands } \\
\text { were considered based on their active } \\
\text { roles in working memory capacity) } \\
\text { AOSPAN AOSPAN }\end{array}$ & $\begin{array}{l}\text { SKY improved working memory } \\
\text { capacity by changing brain } \\
\text { rhythms = energy utilized more } \\
\text { efficiently while performing the task } \\
\text { - SKY = efficient use of energy + PSD }\end{array}$ & $\begin{array}{l}\text { Small sample- Small sample } \\
\text { E No subjective measures }\end{array}$ \\
\hline
\end{tabular}


SKY

ON continued normal activities

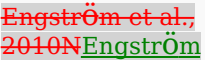

$\underline{\text { et al. }} .12$

$\underline{N}=8$ healthy subjects less than 2 years of meditation (5 Kundalini \& 3 ACEM) practice (min 2*/wk for 21 months) $\times /$ wk for $6-24$ months)

\section{Field et al. $.37 \quad \underline{N}=38$ adults did 20-min Ta chi/yoga class \\ Cross sectional study}

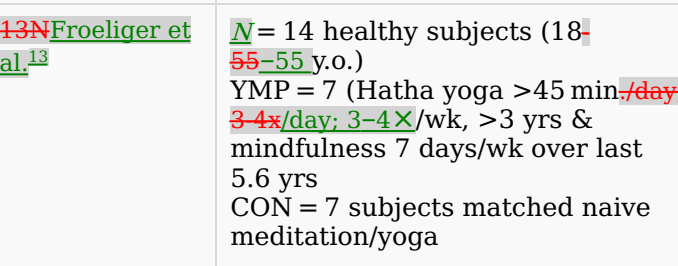

$\underline{N}=47$ healthy subjects YOGA $=16$ (Kripalu yoga) MED $=16$ (Vipassana) CON $=15$ (less than 4 yoga or $m$ Cross in last year

And replication study

$15 \mathrm{~N}=118(55-\underline{N} \equiv \underline{118 \text { (55-79 y.o.) healthy }}$ Gothe et al sedentary subjects

YOGA $=61$

or a stretching control group $\mathrm{CON}=57$

$3 * \underline{\mathrm{X}} /$ wk for $1 \mathrm{~h}$ for 8 -wk period

Hölzel et

$\underline{N}=30$ healthy subjects

MED $=15$ Vipassana ( 7.9 years

$2 \mathrm{~h} /$ day)

$\mathrm{CON}=15$ meditation naive

matched

Cross sectional
Investigate whether moderately experienced meditators activate HIP and PFC during silent mantra meditation

- Determine the immediate effects of a combined form of Tai chi/yoga

- Investigate GMV differences etween YMP and matched CON

BAI (anxiety).

PANAS (State-dependent mood)

Anatomical MRI Anatomical MRI

- Explore differences in whole brain resting-state FC between

experion,

matched controls

Determine if yoga practice resulted in improved executive function

- Investigate differences in brain activation during meditation between meditators and nonmeditators meditation in prone position

on-off block design

performed

blocks), alternating meditate and

Pre-and post- Pre- and post-Ta

STAI, EKG, EEG and math

computations

executive function: - Task switching paradigm self-reported stress and anxiety - State sub-scale of STAI cognitive tes

Block-design fMRI study that elosed) eves closed for the gamma (F8 channel), alpha heta 2 (F7 and FC5) bands Chases of Alpha energy $\uparrow$ Alpha energy $\uparrow$ in retrieval phase

associated with

-

RI obtained during silent mantra

- Each block $=2$ min (total of 8

chi/yoga effects were assessed using failures on the CFQ (positively

Resting-state fMRI based measures

YOGA \& MED = stronger FC within - Running memory span \& n-back task ( $\uparrow$ cortisol levels \& poor cognitive -14-i14-Item Perceived Stress Scale

- salivary cortisol samples pre \& post \begin{tabular}{l|l} 
included $6 * x$ & $\begin{array}{l}\text { stronger activations in the rostral ACC } \\
\text { and the dorsal medial PFC bilaterally }\end{array}$
\end{tabular} (2) mental arithmetic (on screen in front of them)

Subjective measure:

and the dorsal medial PFC bilaterally
- Significant activation in the bilatera HIP/paraHIP formations, bilateral middle cingulate cortex and the

bilateral precentral cortex

- No activation in ACC, and only small activation clusters in PFC

- Heartrate increased during exercise $-\uparrow$ relaxation, $\downarrow$ anxiety, trend $\uparrow$ EEG theta activity

$-\uparrow$ relaxation may

have $\uparrow$ speed + accuracy on math

computations post class

-YMP group exhibited greater GMV in frontal, limbic, temporal, occipital, and cerebellar regions;

- YMP significantly fewer cognitive failures on the CFQ (positively
correlated with greater GMV areas correlated with

listed above) the duration of yoga practice

-- YOGA \& MED had significantly greater degree centrality in the caudate than CON

- Not driven by single connections but 列 basal ganglia cortico-thalamic feedback loops vs CON

YOGA $\uparrow$ accuracy executive function

performance) at follow up

- Change in cortisol levels \& selfreported stress and anxiety levels predicted performance on the running span task, n-back working memory and task switching paradigm

Very small sample No control37N Very

small sample

No control-2 forms of exe- No control

$=2$ forms of exe

No long-term effects studied

Description of exe protocol

- Preliminary study cross-sectional - Same population as other study by Froeliger et al. awareness section)

- Subjects were told not to meditate during resting-state scan

Datom of subset of individuals previously investigated (.22 Lazar et al.
see body awareness table)

RCT $-\underline{R C T}$

No neuroimaging technique but use of vs $\mathrm{CON}$

- Arithmetic, differs from the meditative state, also the external (vs internal) focus, open (vs closed) eyes, preparation for response (vs quiet) 


\begin{tabular}{|c|c|c|c|c|c|}
\hline & & & & & \\
\hline $\begin{array}{l}\text { 57NLuders et } \\
\text { al. } .57\end{array}$ & $\begin{array}{l}N=60 \\
\text { MED: } 30 \text { CON: } 30 \text { matched non- } \\
\text { meditators (obtained from the } \\
\text { ICBM database of normal adults) }\end{array}$ & $\begin{array}{l}\text { - Establish the presence } \\
\text { and direction of callosal differences } \\
\text { between long-term meditators and } \\
\text { well-matched controls }\end{array}$ & $\begin{array}{l}\text { - DTI in combination with structural } \\
\text { MRI } \\
\text { - Callosal measures of tract-specific } \\
\text { FA }\end{array}$ & $\begin{array}{l}\text { - Callosal measures were larger in } \\
\text { MED in anterior callosal sections } \\
\text {-inncreased FA within Fminor but not } \\
\text { Fmajor } \\
\text { - differences between MED \& CON in } \\
\text { rostral body and posteriorly, involving } \\
\text { large parts of anterior midbody and } \\
\text { posterior midbody }\end{array}$ & $\begin{array}{l}\text { - Neuroimaging only Neuroimaging only } \\
\text { - Cross sectional study } \\
\text { - Control from ICBM database }\end{array}$ \\
\hline $\begin{array}{l}\text { Trakroo et al., } \\
\text { 2013Noo et al. }\end{array}$ & $\begin{array}{l}\underline{N}=80 \text { healthy male police } \\
\text { trainees divided in: } \\
\text { Group 1: Asana } \\
\text { Group 2: Pranayama } \\
\text { Group 3: Asana + pranayama } \\
\text { Group 4: Control } \\
\text { All received a training of } 4 \text { days a } \\
\text { week for } 6 \text { months during their } \\
\text { police training }\end{array}$ & $\begin{array}{l}\text { 1-1-Evaluate the effect of } \\
\text { asana + pranayama on neurological } \\
\text { and neuromuscular functions in } \\
\text { healthy human } \\
\text { 2-Determine-Determine differential } \\
\text { effects between training in asana, } \\
\text { pranayama + combination }\end{array}$ & $\begin{array}{l}\text { - EEG, NC, EMG, VEP, ART were } \\
\text { recorded before and after the } \\
\text { training period } \\
\text { - NC, EMG, and VEP data were } \\
\text { obtained from } 28 \text { subjects; EEG data } \\
\text { from } 48 \text { subjects; and RT from } 67 \\
\text { subjects }\end{array}$ & $\begin{array}{l}\text { - Alpha, theta, } \& \text { total power EEG } \uparrow \\
\text { asana training } \\
\pm \downarrow \text { visual reaction time }+\downarrow \text { in red- } \\
\text { green discriminatory reaction } \\
\text { time: } \uparrow \text { processing of visual input. } \\
\pm \downarrow \text { resting EMG voltage: } \uparrow \\
\text { muscular relax after pranayama } \\
\text { - Beta, theta, and total power of EEG } \\
\uparrow ; \text { ART and red-green discriminatory } \\
\text { reaction times } \downarrow \text { more alert state } \& \\
\uparrow \text { central neural processing } \\
\text {-asana }+ \text { pranayama } \\
\uparrow \text { Asana } \pm \text { pranayama } \uparrow \text { motor } \& \\
\text { sensory nerve conduction } \\
\text { - Total power of EEG, alpha, and theta } \\
\text { power, delta } \% \uparrow \text { while reaction time } \\
\downarrow\end{array}$ & $\begin{array}{l}\text { - Inability to complete all the } \\
\text { electrophysiological tests in all the } \\
\text { participants } \\
\text { - All participants continued their police } \\
\text { trainee to the same extent during the } \\
\text { study (control group included) }\end{array}$ \\
\hline
\end{tabular}

\section{Discussion}

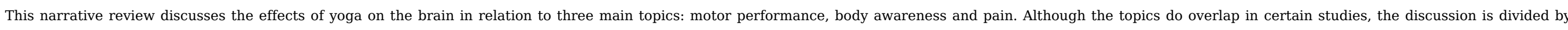
theme and a summary of the three themes is presented at the end of the section.

\subsection{The Effects of Yoga on the Brain in relation to Motor Peffects of yoga on the brain in relation to motor performance}

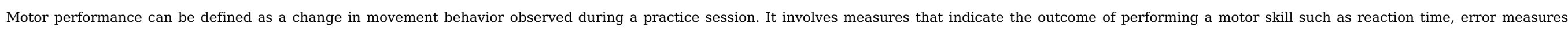

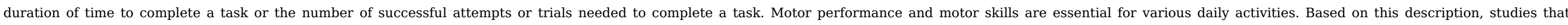
encompass any sort of motor learning, the outcome of performing a motor skill were included in this review. The details of the studies discussed in this section are highlighted in Table 2.

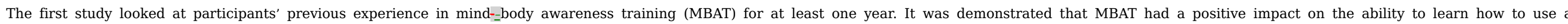

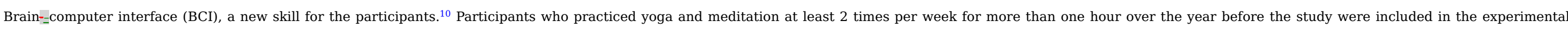

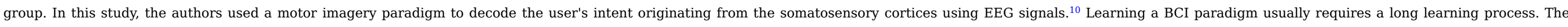

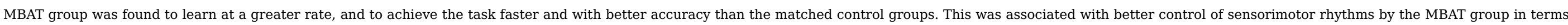
of greater magnitude of the spectral power in this band.

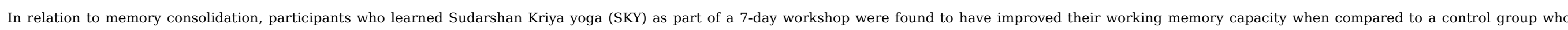

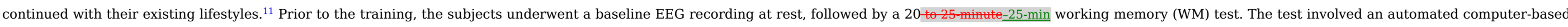

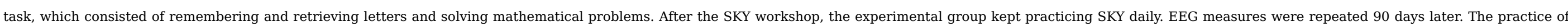

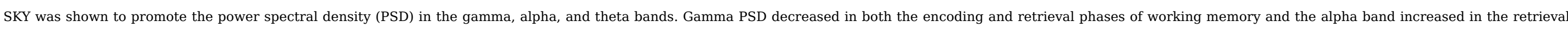
phase following SKY, while theta rhythms were associated with memory consolidation. 


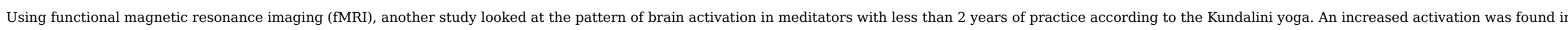

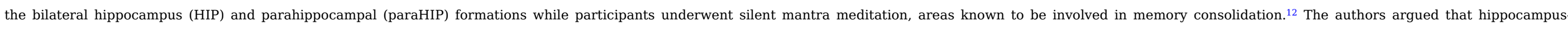

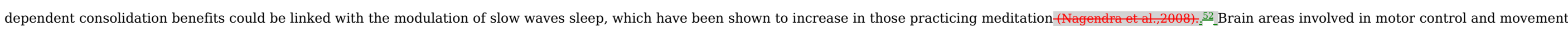
execution such as the bilateral middle cingulate cortex and the bilateral precentral cortex also showed significantly greater activation during meditation.

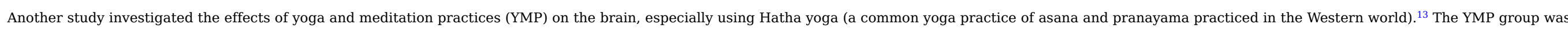

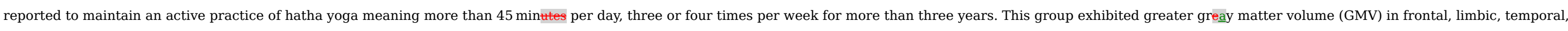

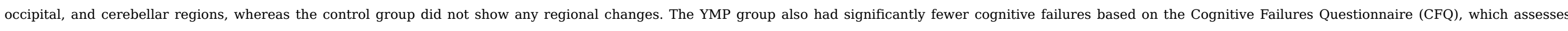

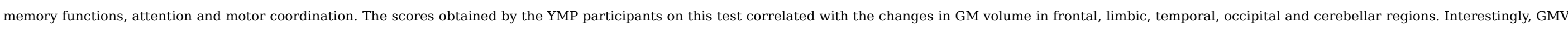

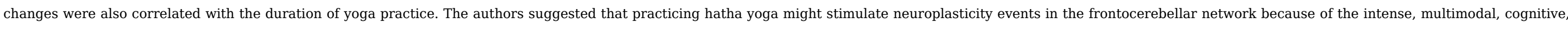
and motor skill learning involved in such practice.

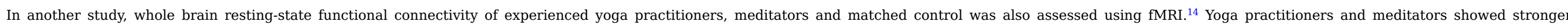

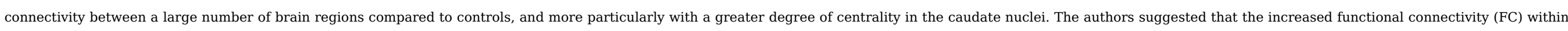

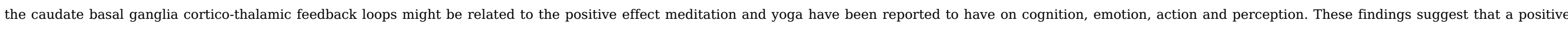

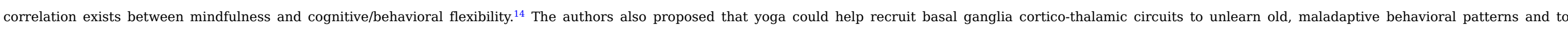
establish new adaptive ones, which could lead to an optimized self-regulation. ${ }^{9}$

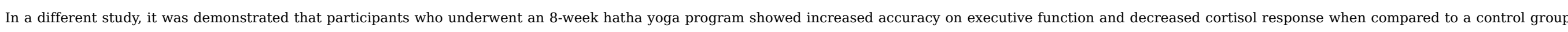

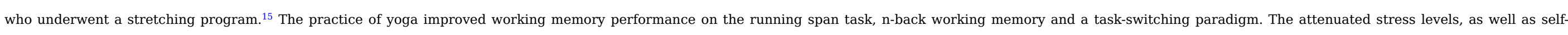
reported stress and anxiety levels, predicted the performance on these tests. ${ }^{15}$

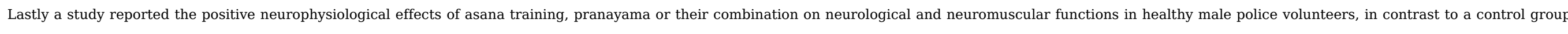

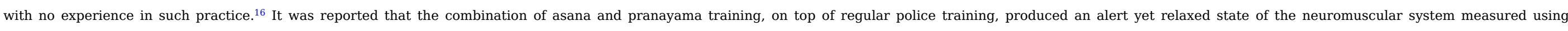

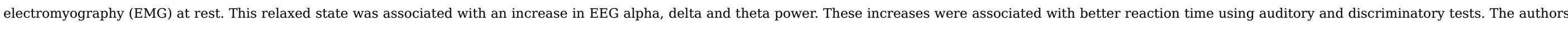

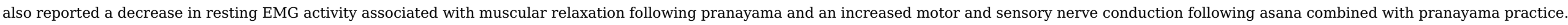

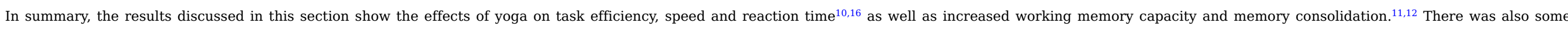

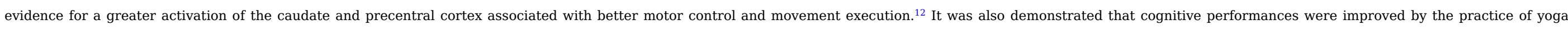

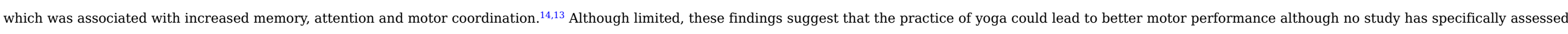
this aspect.

\subsection{The Effects of Yoga on the Brain in relation to Body Aeffects of yoga on the brain in relation to body awareness}

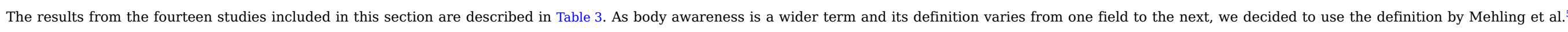

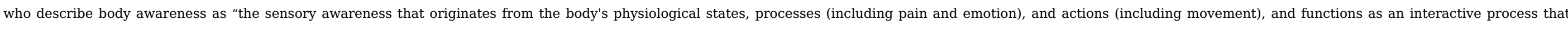
includes a person's appraisal and is shaped by attitudes, beliefs, and experience in their social and cultural context". ${ }^{17}$

Table 3 Effects of yoga on the brain in relation to body awareness.

\section{alt-text: Table 3}

Reference

Sample

20 healthy individuals
MED: 10 experienced

\section{Method}

- Investigate the temporal dynamics of oscillatory changes during Sahaj

\section{Measures}

EEG measure at- EEG measure at baseline and
during intervention session:
Results

-- Distinct meditative states $=$ distinct changes in spectral powers:
Comments

- Short term effects, cross sectional 

long term)

$=12$ meditation

naive

\begin{tabular}{l|l}
$\underline{\text { Braboszcz et }}$ & $\begin{array}{l}\text { 20 meditators from the } \\
\text { Vil. }\end{array}$ \\
& 27 massanatitators from \\
& Himalayan Yoga \\
& Tradition, \\
& 20 meditators from Isha \\
Shoonya Yoga tradition \\
and 32 controls
\end{tabular}

\section{Cohen et al. ${ }^{20} 4$ naive subjects:} men/2 women mean age of 45

\section{Froeliger et}

al.
- Investigate whether MED affects self-referential processing and associated with DMN, either as

short (state)-_or long-term (trait) effects

Examine the differences in brain activity between meditation practitioners and non-practitioners

- EEG $\underline{1 / 2} \equiv \underline{2 \text { then } 1}$

\section{-12 wk IY training} including ) asanas,2) pranayama,(1) asanas, 2) pranayama 3) a guided relaxation with

- Investigate the effects of meditation experience and on multiple RSNs MED: two 5 min scans,

1 -rest eyes closed, 2 -rest eyes

\section{closed,}

\section{$\underline{\text { closed, }}$-meditating}

$\mathrm{CON}$ : one scan resting-state eyes closed

Assess which brain regions were structurally and functionally associated with the state of mental silence in long-term meditators of SYM

Compare the regional GM concentration of mindfulness meditators in the whole brain to
that of people without meditation

- Resting-state EEG recorded pre- and post-task - Time production task

 parietal-occipital and midline and the mean log spectral power was calculated separately for each RO

- Pre-post training measures of SPECT OFC , disfer mor frontal, superior frontal, dLPFC, , midbrain, cerebellum, cingulate gyrus

- fMRI

- Regression analyses of the relations between years of meditation practice and RSNs-FC and MED-FC were conducted

- MR-based techniques (VBM \& FC): MED: measured in 3 phases: $1-$ RS. 2 - RS. $2-$ structural morphometry data collected, and MED instructed to start meditating. 3-_- Measure of MS CON: measured in 2 phases. 1-_ RS identical to MED. 2-_ Subjects watched entertainment video when structural morphometry data was collected using identical acquisition parameters as MED.

- MR-based VBM

(ROI: bilateral DLPFC, ACC, HIP, left inferior temporal gyrus and left postcentral gyrus right
anterior insula, (the standard mask for the right
$-2 \times 20$ min(1-MED 2 IMW $) \cdot(1 / 2=1$ then 2; other $1 / 2$ $=2$ then 1$)$ (1-MED 2-IMW). (1/2 $=1$ then 2 ; othe

MED: 8 min meditation

$\mathrm{CON}: 8$ min relaxation $\underline{8}$ min relaxation

experience before fter session

IM

\begin{tabular}{l|l} 
Pre-post training measures of SPECT & $-s$ \\
Significant $\downarrow$ between pre and post program
\end{tabular} temsorim, inferior \& superior parietal, occipital,

GM left inferior temporal gyrus predictable by
Enhanced Theta band activity during MED in frontal areas

editation experience of Emergence of slow frequency waves in attention- Increased frontal the

frontal theta activity $=$ deactivation of parietal-occipital areas

EEG gamma power MED a trait lower frontal gamma activity $\&$ longer time durations negatively correlated with front gamma activity

State and trait increase in posterior gamma power without a link to proficiency

MED had higher parieto-occipital gamma plitude vs CON during MEDIT and IMW Positively correlated with meditation experience roup compared to all the others in MEDIT and MW

Lower $10-11 \mathrm{~Hz}$ activity in the Himalayan yoga group during MEDIT

MED practice correlated to changes in the EEG gamma frequency range commonly baseline scans in the right

cortex, sensorimotor area. - Significant difference between pre and post \% activation in the right dorsal medial frontal lobe, prefrontal cortex, and right sensorimotor cortex - MED exhibited greater RSN-FC within the DAN between the DAN and DMN and Salience network $\downarrow$ FC between the DAN, dmPFC, insula. -pPositive correlations between years of experience and MED-FC between DAN, thalamus, and anterior parietal sulcus; negative correlations between DAN, lateral and superior parietal, and insula

- GMV in medial prefrontal cortex were positively correlated with the subjective perception of the depth of mental silence inside the scanner - Significantly increased FC between this area and meditation-state insula/putamen during a connectivity with the right

thalamus/parahippocampal gyrus during the meditation-state and the RS

- Capacity of MED to establish a durable state of mental silence inside an MRI scanner associated with larger GMV in a medial frontal region

MED: MED: $\uparrow$ GM right anterior insula, left inferior temporal gyrus and right HIP amount of meditation training
- Independent component analysis was used to show not originate in eye or muscle artifacts ontrol-Small sample No control Case study part of larger study

Changes may relate to any or all the components IY program

\section{-Small sample- $\underline{\text { Small }}$}

\section{sample}

Liberal significance - Short durati

mert duration of

- Meditation in the scan

were scanned twice,

were scanned twice,

controls were
scanned once

- Cross-sectional study

- Subjective measure of depth of meditation known as mental silence was used

No other measures than neuroimaging that gamma activity did

\section{Small sample-Ne}


valuate whether

ndogenous dopamine release increases during loss of executive control in Yoga Nidra meditation

\section{Lazar et al..$^{22}$}

$N=35$

MED $=20$ western

practitioners

$\mathrm{CON}=15$ matche

healthy subject no

experience in meditation

or yoga

23NLazar et al. $.23 \quad \underline{N}=5$ Kundalini meditators of min. 4 yrs experience

25N Tang et al. ${ }^{25}$

$\underline{N}=86$ without training experience randomized undergraduates assigned 2 experiments (IBMT) $\hat{N} \underline{N}=46$ (I: brain imagin $\&$ physiological) $N \underline{N}=40$ (II: EEG \& physiological)

Tang et al..$\underline{24}$

$N=45$ randomized undergraduates to IBMT or relaxation $11 \mathrm{~h}$ of training, $30 \mathrm{~min} / \mathrm{session}$ over 1-mo period.

\section{NVestergaard- $\underline{N}=20$}

Poulsen et al. .59 MED $=10$ (in the Dzogchen tradition of Tibetan Buddhism) CON $=10$ healthy matched non-meditators thickness in brain regions meditators to evaluate cortical plasticity

Identify brain foci of activity that re modulated by a very simple form of meditation raining on brain and physiologic measures; relationship between

brain networks \& ANS during

Investigate if

$11 \mathrm{~h}$ of training with IBMT over 1 mo would $\uparrow \mathrm{FA}$ in anterior coron radiata stem regions of experienced meditators compared with agematched non-meditators regular yoga practice performed
MRI brain scan

5 ROI: right caudate, left caudate, right corticostriatal, putamen, left putamen and ventral striatum

$€$ Two C-raclopride PET scans: $1-\_$attending to speech with eyes closed, 2- - during active meditation.

-5 of 8 participants underwent EEG data collection

-Questionnaire to assess pleasure, relaxation, awakeness \& awareness

Investigate differences in cortical

(attention and sensory processing)

\section{MR-based technique-MR-based technique}

Explore the effects of a 5 day IBMT

training in subjects no experience - EEG collected at baseline (eyes closed), before
and after training

Observe GM density in lower brain

\section{fMRI Heart rate $\mathrm{fMR}$}

Heart rate

Respiration rate

- End-tidal $\mathrm{CO}_{2}$

$-\mathrm{O}_{2}$ saturation levels

- Heart rate, SCR, belly respiratory amplitude,

and chest respiratory rate

- SPECT scanner (2 scans before and after

and after training

- Structural MR-based techniques including DTI - Data acquired before and after training

- Structural MR-based technique

RECOGNISE app*, evaluating accuracy and
GM medial OFC positively correlated with cumulated hours meditation training OFC not found to be greater in MED vs $\mathrm{CON}$

- In MED, C-raclopride binding in ventral striatum endogenous dopamine release

- Reduced raclopride binding correlated

significantly with increase in EEG theta activity action during meditation, along with heightened

I MED: Thicker right middle and superior frontal differ significantly between the groups for either hemisphere

- stronger subgenual and adjacent ventral ACC

cortex activations (including Wernicke's area) than IBMT brain stem speed of laterality task for 1.40 basic images of yoga) for either response time or accuracy decreased by $7.9 \%=$ to a $65 \%$ increase in - All participants reported a decreased desire for sensory imagery sulci (BA9--10), PFC and right anterior insula

- $\uparrow$ PFC thickness in older participants,

Mean thickness across the entire cortex did not

$\uparrow$ in putamen, midbrain, pregenual ACC, HIP and paraHIP formations, prefrontal, parietal and temporal cortices, precentral and postcentral gyri activity in IBMT

-Frontal midline ACC theta was correlated with high-frequency HRV frequency HRV

After training: $\downarrow$ HR, $\uparrow$ belly respiratory

amplitude, $\downarrow$ chest respiratory rate, $\uparrow$ high

$\mp$ Relaxation: more frontal, temporal, and parietal

IBMT increases FA, in left anterior corona radiate, adjacent left $\&$ right superior corona radiate

-FA $\uparrow$ in body and genu of corpus callosum, superior corona radiata, and superior longitudinal fasciculus

- No change GM both groups

- $\uparrow$ GM density but no volume differences in MED in lower brain stem-medulla oblongata -Separation of GM densities between groups in

$\uparrow$ GM densities in left superior frontal gyrus BA 10 and left inferior frontal gyrus-pars triangularis BA 45A) anterior lobe of cerebellum bilaterally $\&$ left fusiform gyrus

- No difference in GM density as a function of total practice hours in any region

-No difference between Groups (yoga and no

Small sample of highly experienced yogis Male only22N Male only

Not monks, typica Western meditation practitioners

\section{Small sample No} ontrol-Small sample No control Cardiorespira-tory measures taken
subjects only

$=\underline{R} C T$

control for variations of physiological indexes over the circadian rhythm;

measurements performed from $2-6 \mathrm{pm} 24 \mathrm{~N}$ to $6 \mathrm{p} . \mathrm{m}$.
- Neuroimaging measures only $=$ Cross-sectional study

- Online study, no controlled environment 

\begin{tabular}{l|l} 
better at a left/right judgement task & $\begin{array}{l}\text { neck 2. } 40 \text { Context images of neck 3. } 40 \text { Basic } \\
\text { than people who did not }\end{array}$
\end{tabular} people who did not design and more accurate at making left/right neck dgements than they were at making left/right-hand judgements, regardless of group
No detailed information on frequency, length, type of yoga practice

ixed sample of people in pain and healthy participants

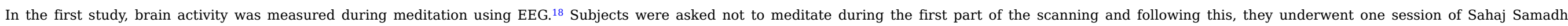

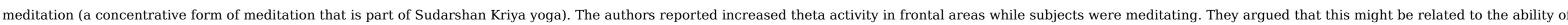

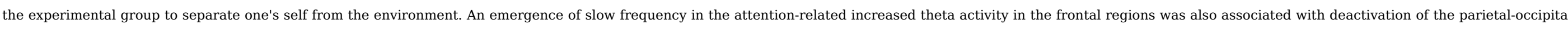

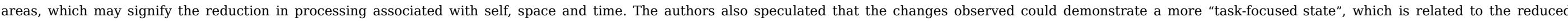

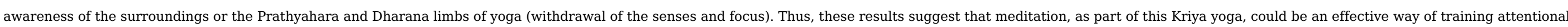
brain networks as they were shown to benefit cognitive processing in humans. ${ }^{18}$

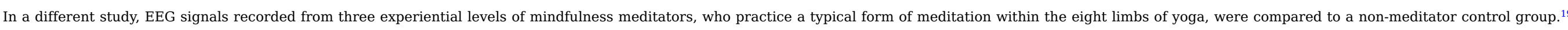

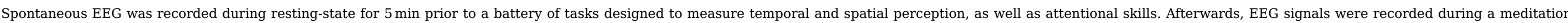

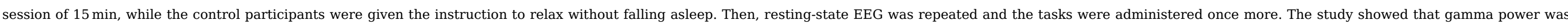

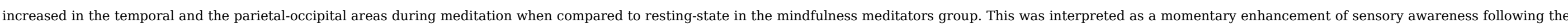

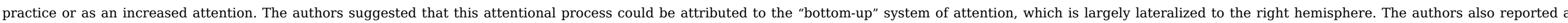

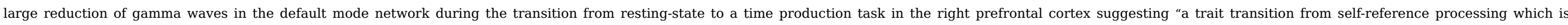

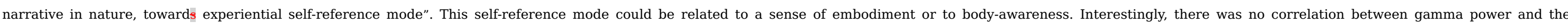

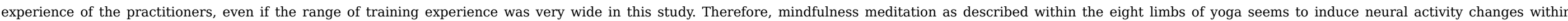
networks associated with self-referential and attention networks during the early stage of the practice.

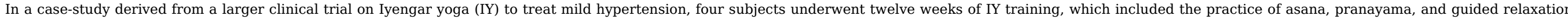

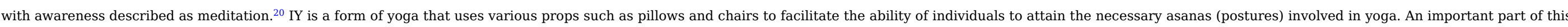

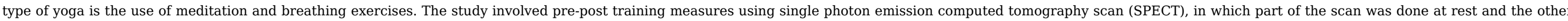

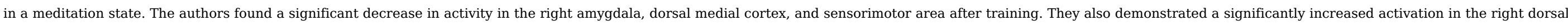

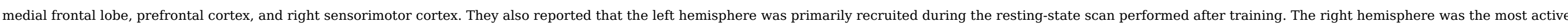

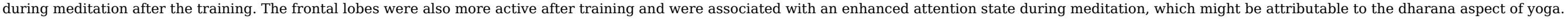

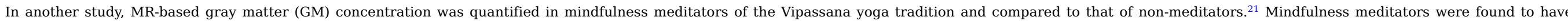

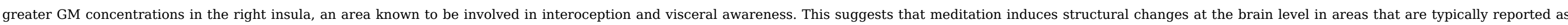
being activated during meditation.

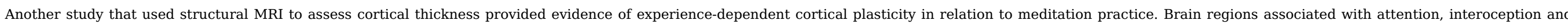

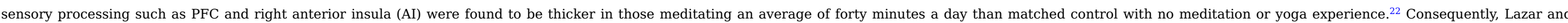
colleagues argued that the regular practice of meditation might delay the onset of age-related cortical thinning in the frontal cortex.

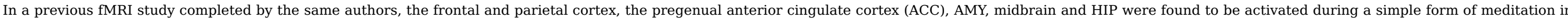

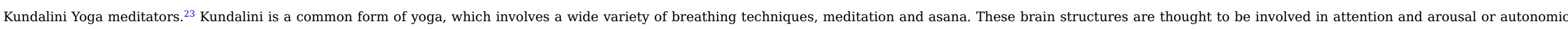
control and may contribute to the meditative state. The authors suggested that the activation observed in limbic regions were most likely modulating the output of the autonomic system.

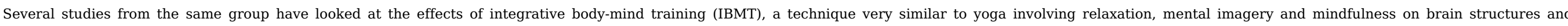




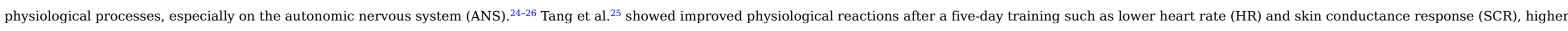

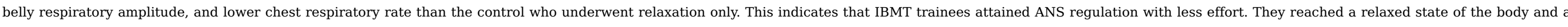

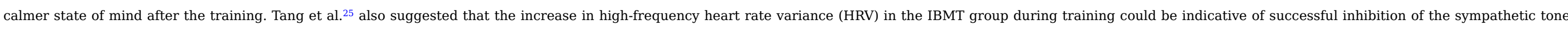

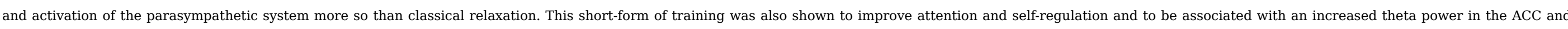

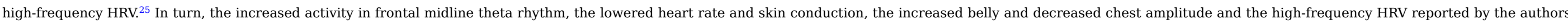
were thought to provide strong evidence for the central and autonomic nervous system to be modulated by such a practice.

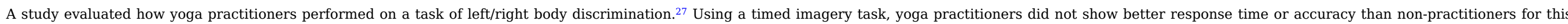

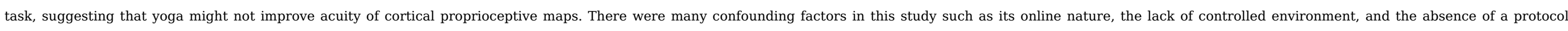

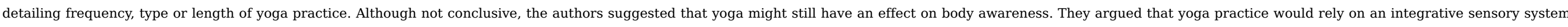
while the task used in their study relied on a visuo-proprioceptive mechanism. Therefore, the task they used might not be the best to evaluate body awareness. This aspect remains to be further clarified.

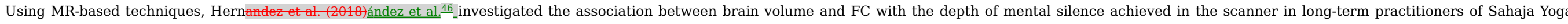

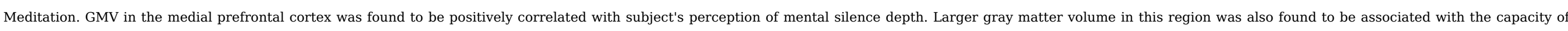

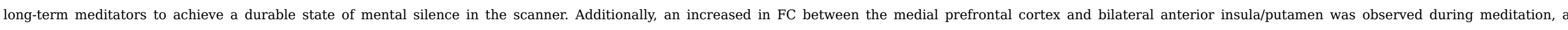

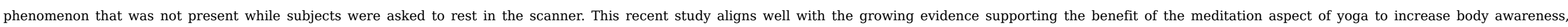
interoception and attentional control.

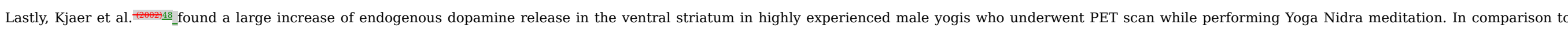

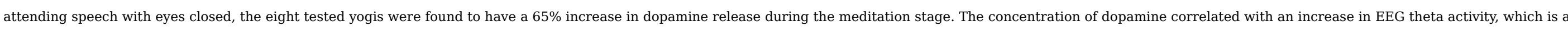

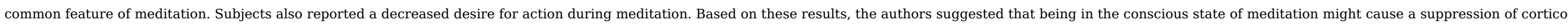
striatal glutamatergic transmission. This in turn would contribute to heightening the attentional control reported by those practicing the meditation aspect of yoga.

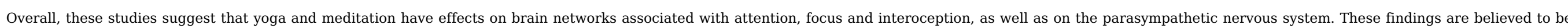
associated with the relaxed state, increased focus and withdrawal of external stimuli described in yoga practice, which is known as body awareness by its practitioners.

\subsection{The Effects of Yoga on the Brain in relation to Peffects of yoga on the brain in relation to pain}

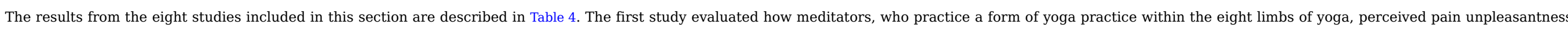

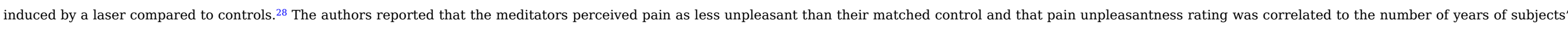

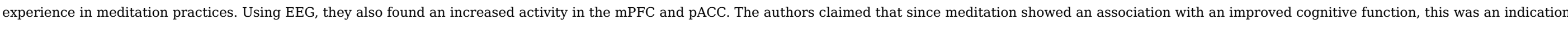

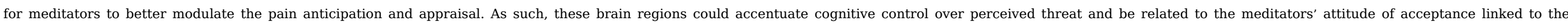
attentional network.

Table 4 Effects of yoga on the brain in relation to pain.

\section{alt-text: Table 4}

Reference \begin{tabular}{l|l} 
Brown CA, Jones & $\underline{N}=27$ \\
AKP, 2010Nand & MEDITATC
\end{tabular} Jones 28 practice type CONTROL: 15 without meditation experience 12 of various

\section{Method}

- Test whether any differences in the affective appraisal of pain could be explained by lower anticipatory neura processing in relation to meditation experience

- Two runs of 15 trials lasting 5 minutes, laser heat of $7 / 10$ every 10 s, preceded by visual anticipation cue

\begin{tabular}{|l|}
\hline \multicolumn{1}{|c}{ Mesures } \\
\hline - Questionnaire for meditation \\
experience; \\
- Anticipatory and EEG pain-evoked \\
ERPs and reported pain \\
unpleasantness (VAS) in response to \\
laser stimuli of matched subjective \\
intensity \\
- ERP data after source estimation \\
\hline
\end{tabular}

Results

- MED: pain as less unpleasant vs controls, with experience correlating inversely with unpleasantness ratings ERP source data for anticipation in MED = lowe activity in MCC vs CON related to lower unpleasantness ratings, (experience predicted) - MED reversed the normal positive correlation between MPFC activity and pain unpleasantness in
- Meditation was not part of the experimental protocol, only meditation experience was investigated -Small sample size29N = 28YOGA: Small sample size 


\begin{tabular}{|c|c|c|}
\hline$\underline{\text { Ceko et al. }} . \underline{29}$ & $\begin{array}{l}N=28 \\
\text { YOGA:14 long term } \\
\text { yoga practitioners } \\
\text { CON:14matehed } \\
\text { eontrol_14 matched } \\
\text { control }\end{array}$ & $\begin{array}{l}\text { Evaluate WM connectivity in long-term } \\
\text { yoga practitioners and its relation to pain } \\
\text { tolerance }\end{array}$ \\
\hline $\begin{array}{l}30 \mathrm{~N}= \\
\text { 34MED:Gard et } \\
\text { al. }^{30}\end{array}$ & $\begin{array}{l}N=34 \\
\text { MED: } 17 \text { mindfulness } \\
\text { practitioners (trained } \\
\text { in Vipassana } \\
\text { meditation) } \\
\text { CON: } 17 \text { matched } \\
\text { healthy control } \\
\text { without meditation } \\
\text { experience }\end{array}$ & $\begin{array}{l}\text { - Investigate the underlying brain } \\
\text { mechanisms by which the state of } \\
\text { mindfulness reduces pain } \\
\text { - MED and CON received unpleasant } \\
\text { transcutaneous electric stimuli of } \\
\text { moderate intensity during a mindfulness } \\
\text { and a control condition (no specific } \\
\text { strategy) }\end{array}$ \\
\hline$\underline{\text { Grant et al }} .{ }^{33}$ & $\begin{array}{l}N=35 \\
17 \text { meditators and } 18 \\
\text { controls } \\
\text { Cross } \\
\text { sectionalstudy study }\end{array}$ & $\begin{array}{l}\text { Investigate whether differences in brain } \\
\text { morphometry are associated with the low } \\
\text { pain sensitivity observed in Zen } \\
\text { practitioners }\end{array}$ \\
\hline$\underline{\text { Grant et al. }} . \underline{32}$ & $\begin{array}{l}N=26 \\
\text { MEDITATORS: } \\
13 \text { healthy Zen } \\
\text { meditators } \\
\text { CONTROL: } \\
\text { 13 matched non- } \\
\text { meditators }\end{array}$ & $\begin{array}{l}\text { - Investigate how Zen reduce } \\
\text { practitioners' activity in executive, } \\
\text { evaluative and emotion areas during pain } \\
\text { (PFC, AMY, HIP) } \\
\text { - Moderate-pain level assessed and used } \\
\text { for trials on six locations on left calf }\end{array}$ \\
\hline $\begin{array}{l}\text { 34NOrme-Johnson } \\
\text { et al. }{ }^{34}\end{array}$ & $\begin{array}{l}N=24 \\
\text { MEDITATORS: } \\
12 \text { long-term TM } \\
\text { (average of } \\
31.3 \pm 2.3 \text { years) } \\
\text { CONTROL: } 12 \\
\text { matched healthy } \\
\text { control interested } \\
\text { learning TM }\end{array}$ & $\begin{array}{l}\text { - Identify if TM has a long-term effect on } \\
\text { pain } \\
\text { 1. Pretest, MED compared } \mathrm{CON}_{-} \\
\text {2. TM taught } 4 \text {-day course, } 20 \mathrm{~min} 2 \\
\text { 5months, } 3 . \times \text { day } 5 \text { months, } \\
\text { 3. Both groups post-tested same protocol }\end{array}$ \\
\hline $\begin{array}{l}6 \mathrm{~N}=28 Y 06 \mathrm{Y}: 14 \\
\text { North- } \\
\text { AmericanVillemure } \\
\text { et al. }{ }^{6}\end{array}$ & $\begin{array}{l}N \equiv 28 \\
\text { YOGA: } 14 \text { North- } \\
\text { American yoga } \\
\text { practitioners (of all } \\
\text { type of yoga) } \\
\text { CONTROL: } 14 \text { matched } \\
\text { eontrol } 14 \text { matched } \\
\text { control }\end{array}$ & $\begin{array}{l}\text { Investigate possible neuroanatomical } \\
\text { underpinnings of the beneficial effects of } \\
\text { yoga }\end{array}$ \\
\hline
\end{tabular}

with LORETA

VOIs were MCC, IPC, mPFC (the mPFC cluster included pACC)

- MRI session including a DTI scan after completing a cold pain tolerance task

- Correlation between FA in

significant brain map clusters and pain tolerance

\section{fMRI-fMRI}

Respiratory rate during scanner Subjective reports:

-Stimulus intensity, Unpleasantness and anticipatory anxiety VAS after

stimulation

- Mood, task difficulty and selfperceived success 7-point Likert

scale pre-post scanning

- Freiburg Mindfulness Inventory

- German Fear of pain questionnaire

Structural MRI scans (ROI: dACC PFC, SI, SII, HIP)

Thermal Pain sensitivity with VAS Five Factor Meditatio questionnaire

\section{fMRI $\mathrm{fMR}$} Participants were instructed to normally would, with eyes closed Medit Mediators were specificed asked to not meditate - Pain perception assessed using electronic VAS measuring intensity and unpleasantness

- Questionnaire of meditation history

- fMRI collected during single-block stimulation along with Pain VAS scale

Expectation measures (subjective question) - Thermal detection and pain Cold pain tolerance Mental strategies used during tolerance task (subjective question) MR-based techniques (voxel-based morphometry, Cortical Thickness analysis, DTI Analysis and anticipation

with lower activity in SII and insula during the pain-evoked response

YOGA: enhanced WM connectivity in pain-related regions, (CC, insula, S2)

- Effects are related to higher tolerance of pain

-MED $\downarrow$ pain unpleasantness by $22 \%$ \& anticipatory anxiety by $29 \%$ during a mindful state. - Reduction $=\downarrow$ activation the lateral PFC and stimulation and increased rostral ACC activation during anticipation of pain

MED = lower pain sensitivity than CON associated with thicker cortex in affective, pain-related brain regions (ACC, bilateral para-HIP gyrus and anterio insula)

MED = thicker cortex dorsal ACC and bilaterally

More experience $=$ thicker GM in ACC, bilaterally in the lower leg area SI + hand area right hemisphere

- MED: higher stimulus intensities than CON - More experienced MED showed the largest activation reductions

MED more robustly activated primary pain processing regions (ACC, thalamus, insula) vs CON showed stronger activation in bilateral DLPFC and AMY, left MFG and right HIP and med PFC/OFC $\downarrow$ Lower pain sensitivity in MED predicted by reductions in $\mathrm{FC}$ between executive and pain-

related cortices

- MED does not significantly differ from CON on Pain VAS, either at pretest, at posttest, or collapsed across trials.

- Both groups, $\downarrow$ pain ratings $25 \%$ from pre to posttesting

- MED showed $40-50 \% \downarrow$ voxels to pain in the thalamus and total brain than $\mathrm{CON}$ -After CON did TM training $\downarrow 40-50 \%$ in thalamus, PFC, total brain, and ACC

-YOGA expected practice to $\downarrow$ reactivity to pain Yogis $>2 x$ Yogis $>2 x$ long as CON \& $\uparrow \mathrm{GM}$ multiple brain regions

Insular GM correlated pain tolerance.

- Insular GM volume in yogis positively correlated

with yoga experience

Yogis have greater left intra-insular WM

connectivity

Yogis: cognitive strategies involving

parasympathetic activation and interoceptive
- Mindfulness meditation during

- Short study description mple size33N Smal sample size

Thermal stimuli applied to calf influenced also by posture Zen meditation

Half of participants had been in previous study by Grant et al

No behavioral data

- Pain same intensity but reduced response to acute pain after TM training

One type of meditation studie - Partial crossover design 


\begin{tabular}{|l|l|l|} 
Zeidan et al. $^{35}$ & $\begin{array}{l}\text { 15 healthy } \\
\text { volunteers without } \\
\text { MED experience }(6 \\
\text { male/9 female) }\end{array}$ & $\begin{array}{l}\text { - Assess the neural mechanisms by which } \\
\text { mindfulness meditation influences pain } \\
\text { - } 4 \text { days of 20 minutes of mindfulness } \\
\text { meditation training }\end{array}$ \\
& & \\
&
\end{tabular}

Tractography)

ASL FMRIVAS FMI-

fMRI

FAS

Painful Thermal stimuli

MRI 1 performed before training

and MRI 2 after 4 days of training

(MRI: $1 / 2$-yos closed; $-1 / 2$

meditation) $1 / 2$ eyes closed; $1 / 2$ awareness to tolerate pain

$\downarrow$ pain-unpleasantness $57 \%=\uparrow$ activity ACC and anterior insula

$\downarrow$ pain-intensity ratings $40 \%=\mathrm{OFC}$ activation and thalamic deactivation

MED $\downarrow$ pain-related activation contra lateral Si

- Brief MED training $\uparrow$ mindfulness skills

MED post training activate SI bilat (nose and

throat) + bilat activation posterior insula SII, AI and ACC

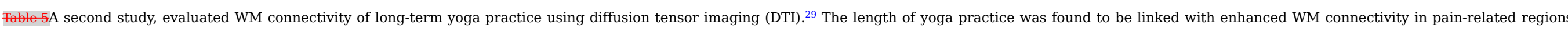
such as CC, insula and SII. These brain changes were also related to higher tolerance of pain for yoga practitioners over the control group (Table 5).

Table 5 Abbreviations used in this review.

\section{alt-text: Table 5}

\section{$\mathrm{AI}$}

ACC

AMY

ANS

AOSPAN

ART

ASL

BA

BAI

BCI

BOLD

$\mathrm{CC}$

CES-D

CFQ

CNS

CON

DAN

DMN

DLPFC

DTI

EEG

EKG anterior insula

anterior cingulate cortex

amygdala

autonomic nervous system

Automated of operation span (15 trial remembering and retrieving letters and solving math problems)

auditory reaction time

arterial spin labeling

Brodmann areas

Beck Anxiety Inventory

brain--_computer interface

blood oxygen level-dependent

Cingulate cortex

Center for Epidemiological Studies-Depression

Cognitive Failures Questionnaire

central nervous system

Control group

Dorsal Attention Network

default mode network

Dorsolateral prefrontal cortex

diffusion tensor imaging

Electroencephalogram

electrocardiogram
- MED might activate cognitive regulation of nociceptive

processing and in reframing the

contextual evaluation of sensory

events

(n)




\begin{tabular}{|c|c|}
\hline EMG & electromyogram \\
\hline FA & fractional anisotropy \\
\hline FC & functional connectivity \\
\hline fMRI & functional magnetic resonance \\
\hline FMI & Freiburg Mindfulness Inventory \\
\hline GM & Gray matter \\
\hline GMV & gray matter volume \\
\hline HIP & Hippocampus \\
\hline HR & heartrate \\
\hline HRV & heartrate variance \\
\hline IBMT & integrative body-mind training \\
\hline ICBM & International Consortium for Brain Mapping database \\
\hline IMW & Instructed Mind wandering task \\
\hline IPC & right inferior parietal cortex \\
\hline ITR & information transfer rate (standard metric of BCI control) \\
\hline IY & Iyengar yoga \\
\hline LORETA & low-resolution electromagnetic tomography \\
\hline MBAT & mind-_body awareness training \\
\hline MCC & midcingulate cortex \\
\hline MED & Meditation group \\
\hline MEDIT & Meditation task \\
\hline MFG & middle frontal gyrus \\
\hline $\mathrm{mPFC}$ & medial Prefrontal cortex \\
\hline MRI & magnetic resonance imaging \\
\hline $\mathrm{msFC}$ & meditation-state FC \\
\hline NC & nerve conduction \\
\hline OFC & Orbitofrontal cortex \\
\hline $\mathrm{pACC}$ & pregenual ACC \\
\hline PANAS & 20-item positive and negative affect schedule \\
\hline $\mathrm{PFC}$ & Prefrontal cortex \\
\hline PSD & power spectral density \\
\hline PVC & percent valid correct \\
\hline ROI & Region of interest \\
\hline RSNs & resting-state networks \\
\hline
\end{tabular}


*RECOGNISE App (Neuro Orthopaedic Institute, Adelaide, Australia)

Online application that has been validated for the recognition of
GL. (Bray H, Moseley GL, 2011) (Parsons LM, Fox, PT-1998), 1998)

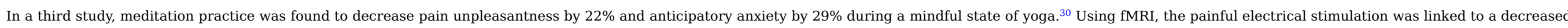

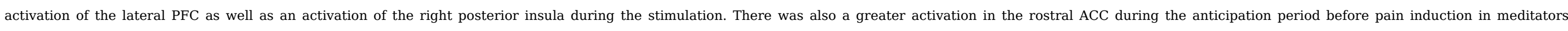

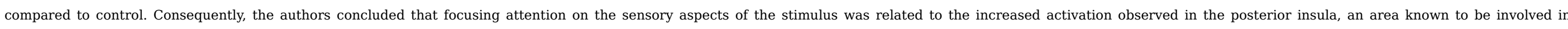

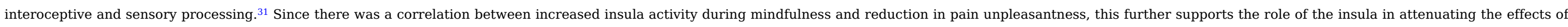
mindfulness..$^{30}$ In other words, the area could be involved in increasing the sensory processing of the sensation itself through a distinctive brain state of cognitive disengagement.

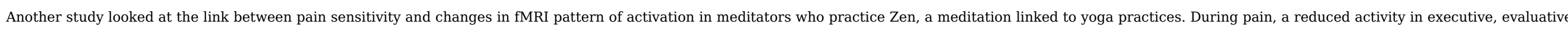

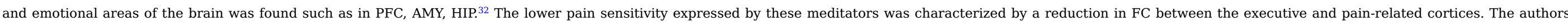

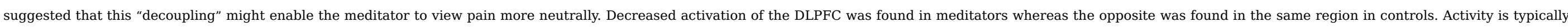

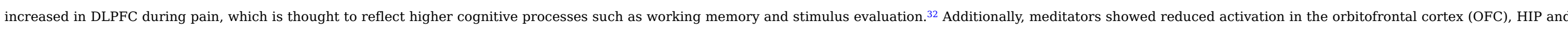

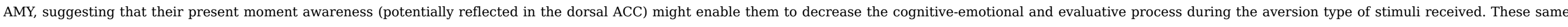

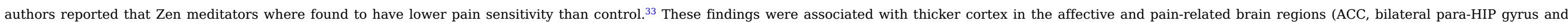
anterior insula) for the meditators.

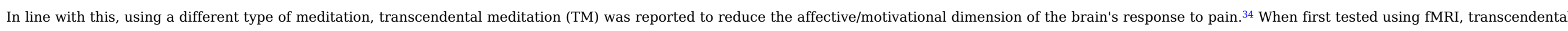

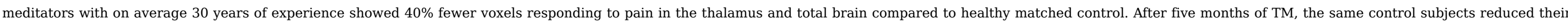

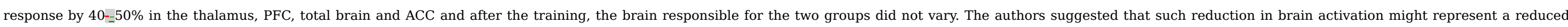

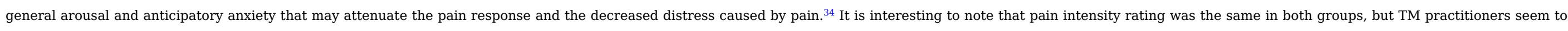
be less distressed as shown by their reduced fMRI pattern of activation. This suggests that expectancy was modulated by the practice of TM, thus altering pain perception. 


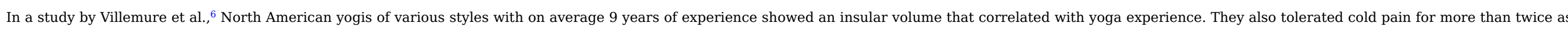

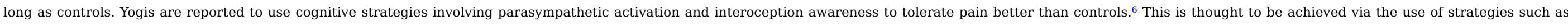
focusing on their breath and on the sensations without reacting to it, relaxing their mind and body and accepting the painful sensation.

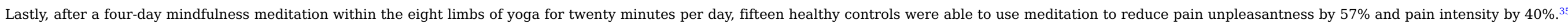

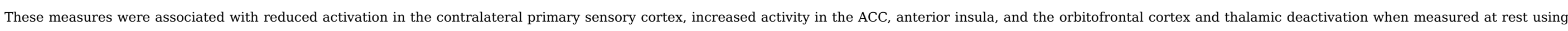

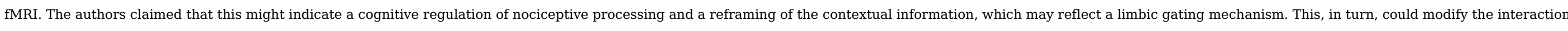

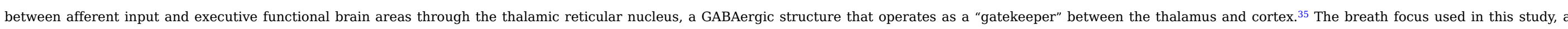
focused-attention type of meditation, may therefore influence pain intensity by altering the expansion of nociceptive input.

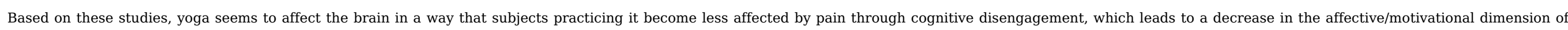

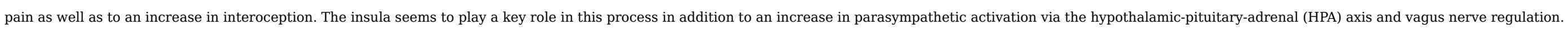

\subsection{Effects of yoga on the brain in relation to motor performance, body awareness and pain}

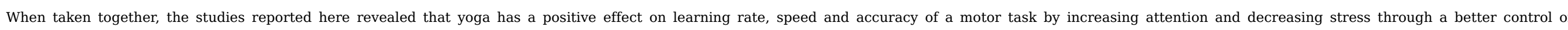

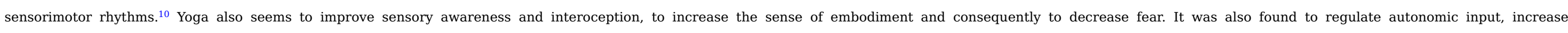

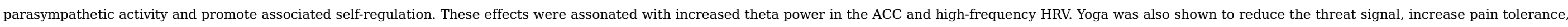

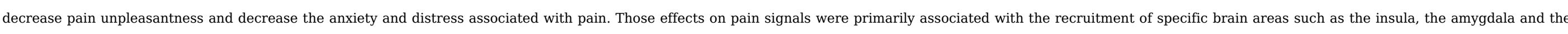

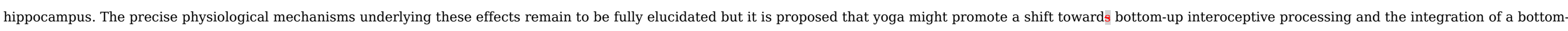

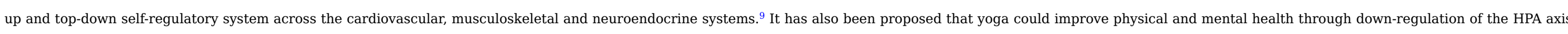

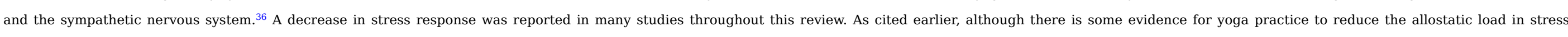

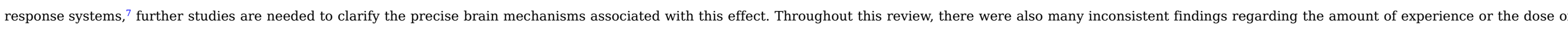

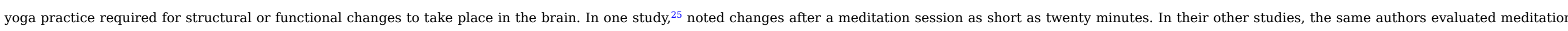

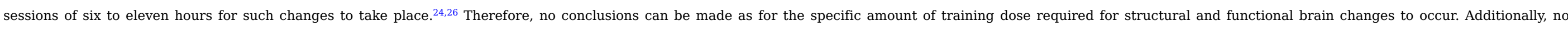
research has been done so far to evaluate the effects of yoga on motor performance per se.

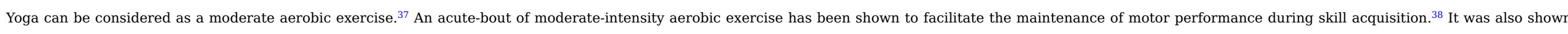

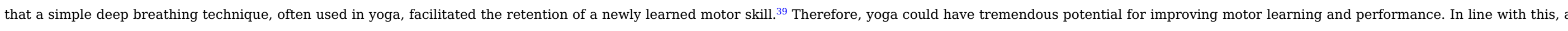

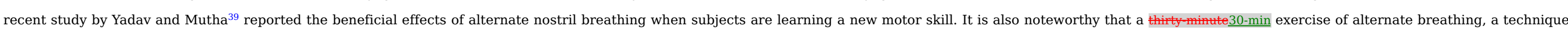

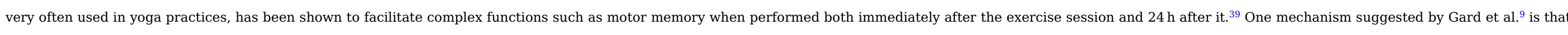

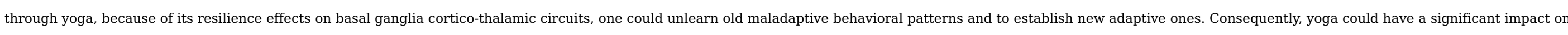

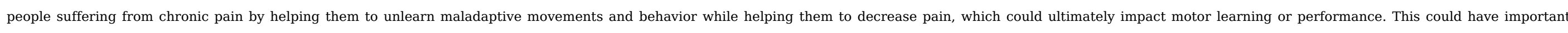

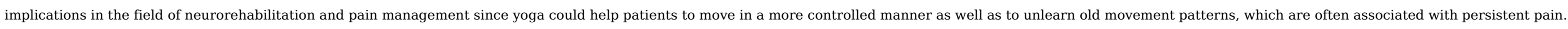

\section{4 $\underline{5}$ Limitations}

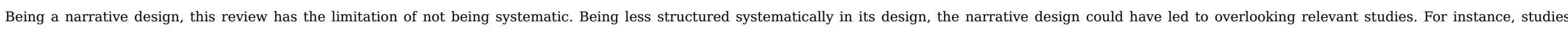

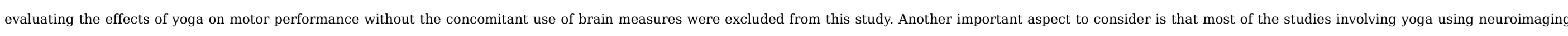

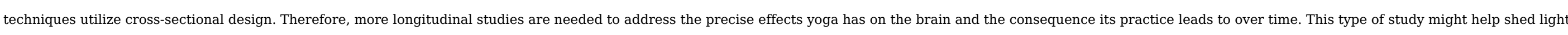

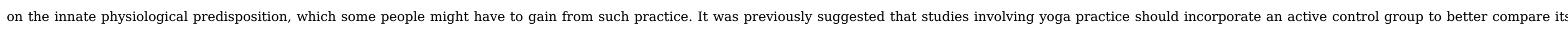

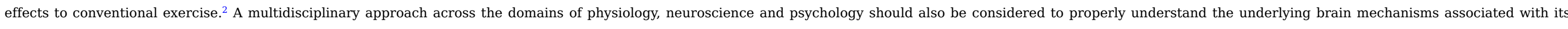




\section{Conclusion}

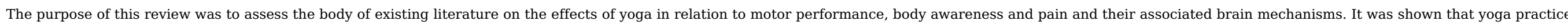

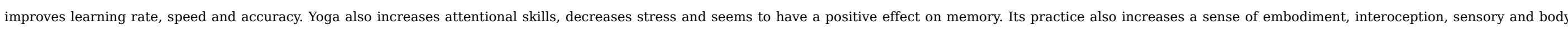

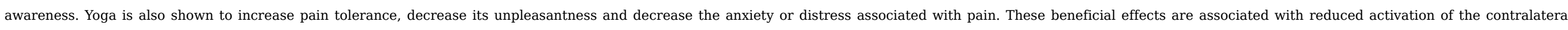

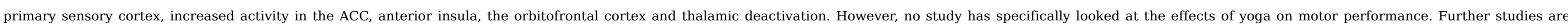

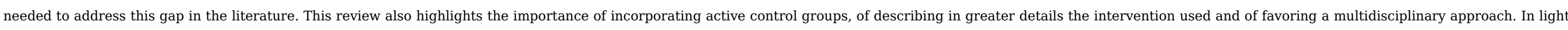

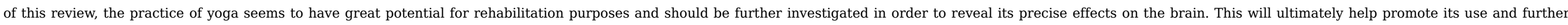
validate its application in clinical settings.

\section{Uncited references}

$41-56 \underline{43-45,49-51,53-56 .}$

\section{References}

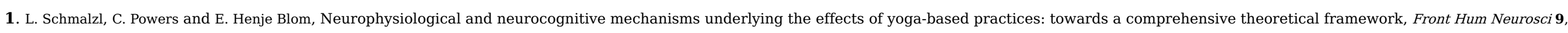
2015, 235, https://doi.org/10.3389/fnhum.2015.00235.

2. T. Field, Yoga research review, Complement Ther Clin Pract 24, 2016, 145-161, https://doi.org/10.1016/j.ctcp.2016.06.005.

3. G. Garner, Medical Therapeutic Yoga, 2016, Handspring Publishing; United Kingdom.

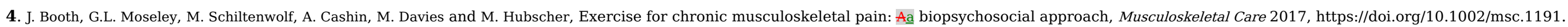

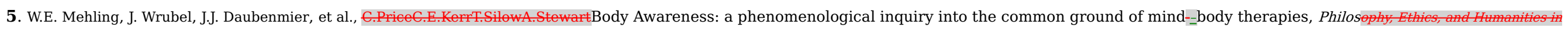
Medieine_Ethics Humanit Med $\mathbf{6}$ (6), 2011, 1-12, https://doi.org/10.1186/1747-5341-6-6.

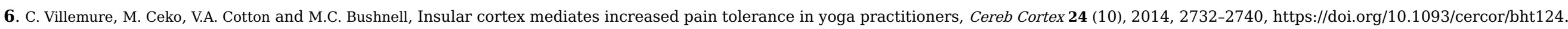

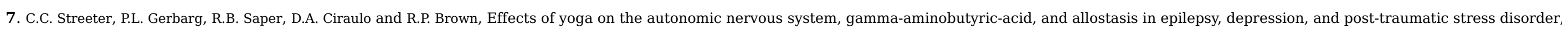
Med Hypotheses 78 (5), 2012, 571-579, https://doi.org/10.1016/j.mehy.2012.01.021.

8. B.K.S. Iyengar, Light on ¥피a, 2015, HarperThorsons; London, England.

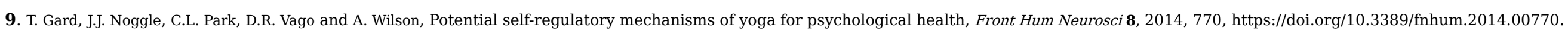

10. K. Cassady, A. You, A. Doud and B. He, The impact of mind-_body awareness training on the early learning of a brain=-computer interface, Technology (Singap World Sci) 2 (3), 2014, 254-260, https://doi.org/10.1142/S233954781450023X.

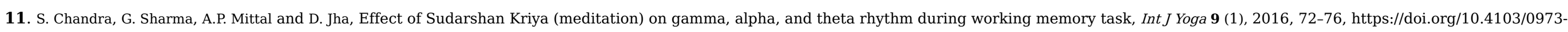
6131.171715.

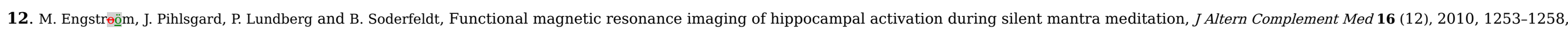
https://doi.org/10.1089/acm.2009.0706.

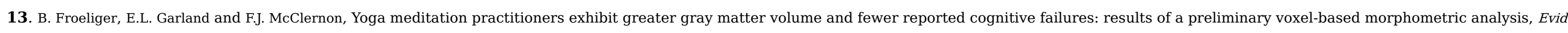




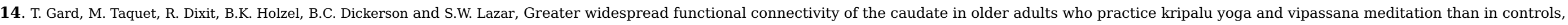
Front Hum Neurosci 9, 2015, 137, https://doi.org/10.3389/fnhum.2015.00137.

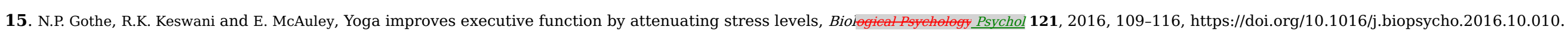

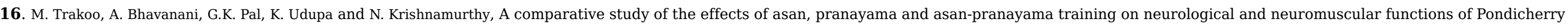
police trainees, Int J Yoga 6, 2013, 96-103, [serial online].

201317 W.E. Mehling, C. Price, J.J. Daubenmier, M. Acree, E. Bartmess and A. Stewart, The Multidimensional Assessment of Interoceptive Awareness (MAIA), PLoS One 7 (11), 2012, e48230, https://doi.org/10.1371/journal.pone.0048230.

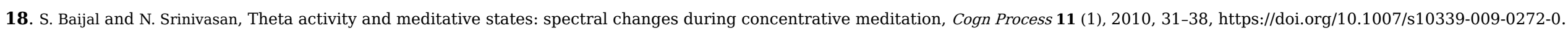

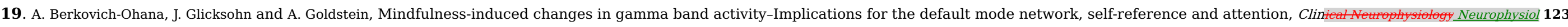
2012, 700-710, https://doi.org/10.1016/j.clinph.2011.07.048.

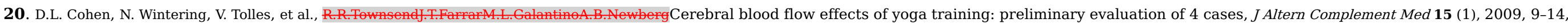
https://doi.org/10.1089/acm.2008.0008.

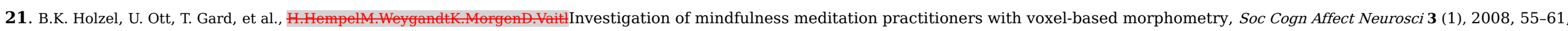
https://doi.org/10.1093/scan/nsm038.

22. S.W. Lazar, C.E. Kerr, R.H. Wasserman, et al., J.R.GrayD.N.GreveM.TreadwayB.FischlMeditation experience is associated with increased cortical thickness, Neuroreport 16 (17), 2005, 1893-1897.

23. S.W. Lazar, G. Bush, R.L. Gollub, G.L. Fricchione, D.S. Khalsa and H. Benson, Functional brain mapping of the relaxation response and meditation, Neuroreport 11 (7), 2000 , 1581-1585.

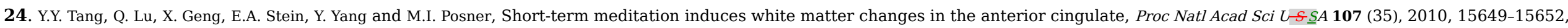
https://doi.org/10.1073/pnas.1011043107.

25. Y.Y. Tang, Y. Ma, M. Fan, et al., H.FengJ.WangS.FengM.FanCentral and autonomic nervous system interaction is altered by short-term meditation, PNAS 106 (22), 2009 , $8865-8870$.

26. Y.Y. Tang, Y. Ma, J. Wang, et al., Y.FanS.FengQ.LuM.I.PosnerShort-term meditation training improves attention and self-regulation, PNAS 104 (43), $2007,17152-17156$.

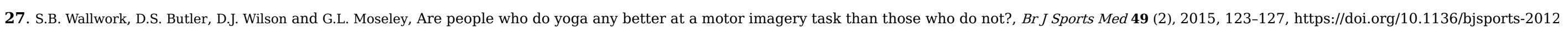
091873.

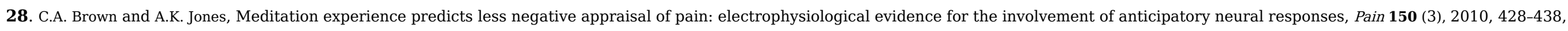
https://doi.org/10.1016/j.pain.2010.04.017.

29. M. Ceko, C. Villemure, V. Cotton and M. Bushnell, White matter alterations in long-term yoga practitioners: a diffusion-tensor imaging study, The Journal ofI Pain 13 (4), 2012, S93, https://doi.org/10.1016/j.jpain.2012.01.385.

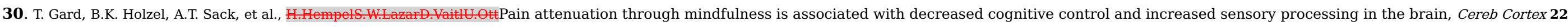
(11), 2012, 2692-2702, https://doi.org/10.1093/cercor/bhr352.

31. A.D. Craig, How do you feel-now? The anterior insula and human awareness, Nat Rev Neurosci 10, 2009, 59-70.

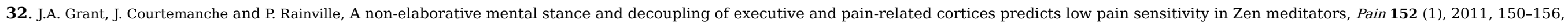


https://doi.org/10.1016/j.pain.2010.10.006.

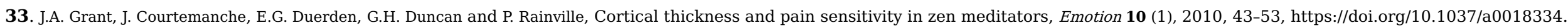

34. D. Orme-Johnson, R.H. Schneider, Y.D. Son, S. Nidich and Z.-H. Cho, Neuroimaging of meditation's effect on brain reactivity to pain, Neuroreport 17 (12), $2006,1359-1363$.

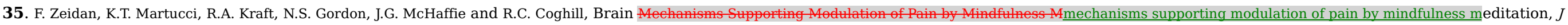
Neurosci 31 (14), 2011, 5540-5548, https://doi.org/10.1523/JNEUROSCI.5791-10.2011.

36. P. Sengupta, Health Impacts of Yoga and Pranayama: A State of the Art Rimpacts of yoga and pranayama: a state-of-the-art review, Int J Prev Med 3 (7), 2012 , 444-458.

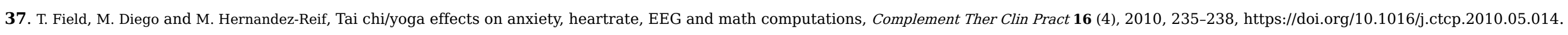

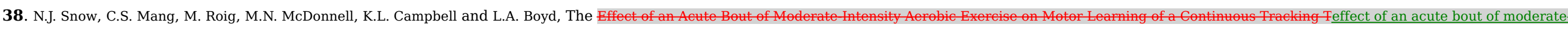
intensity aerobic exercise on motor learning of a continuous tracking task, PLoS One 11 (2), 2016, e0150039, https://doi.org/10.1371/journal.pone.0150039.

39. G. Yadav and P.K. Mutha, Deep Breathing Practice Facilitates Retention of Nowly Learned Motor Sbreathing practice facilitates retention of newly learned motor skills, Sci Rep 6, 2016, 37069, https://doi.org/10.1038/srep37069.

40. K.J. Sherman, Guidelines for developing yoga interventions for randomized trials, Evid Based Complement Alternat Med 2012, 2012, 143271, https://doi.org/10.1155/2012/143271.

41. Bridgebuilders to awareness in healthcare group description. Retrieved on February 28th 2017 fromBridgebuilders to Awareness in Healthcare Group Description. https://www.facebook.com/groups/bridgebuilderstoawarenessinhealthcare; Retrieved 28.02.17.

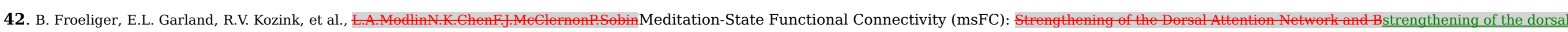
attention network and beyond, Evid Based Complement Alternat Med 2012, 680407, https://doi.org/10.1155/2012/680407.

43. N.P. Gothe, M.B. Pontifex, C. Hillman and E. McAuley, The acute effects of yoga on executive function, 2013 , 488-495.

44. U. Halsband and R.K. Lange, Motor learning in man: a review of functional and clinical studies, J Physiol Paris 99 (4-6), 2006, 414-424, https://doi.org/10.1016/j.jphysparis.2006.03.007.

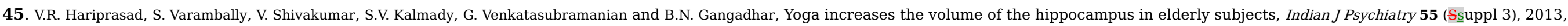
S394-S396, https://doi.org/10.4103/0019-5545.116309.

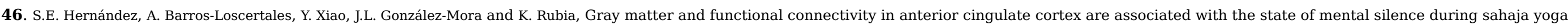
meditation, Neuroscience 371, 2018, 395-406, https://doi.org/10.1016/j.neuroscience.2017.12.017.

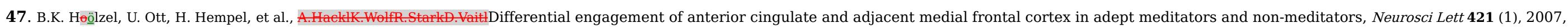
16-21, https://doi.org/10.1016/j.neulet.2007.04.074.

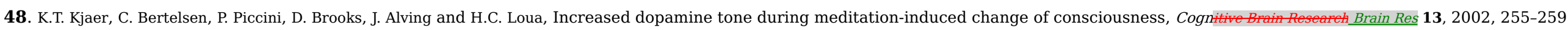

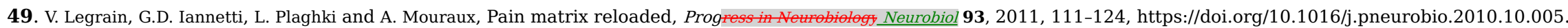

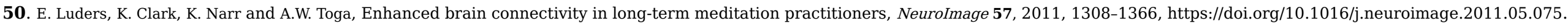

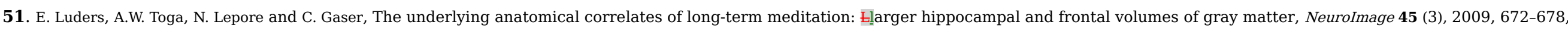
https://doi.org/10.1016/j.neuroimage.2008.12.061.

52. R.P. Nagendra, S. Sulekha, B.R. Tubaki and B.M. Kutty, Efficacy of mindfulness meditation practice on sleep architecture, J Sleep Res 17, $2008,251$. 


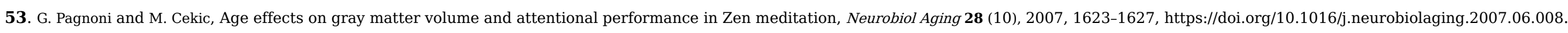

54. Pain definition (IASP) Retrieved April 10, 2017, fromPain Definition (IASP). http://www.iasppain.org/Taxonomy\#Pain i Retrieved 10.04.17.

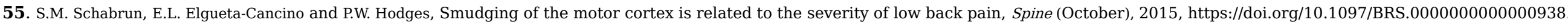

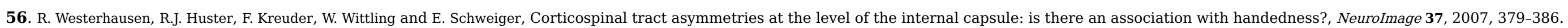

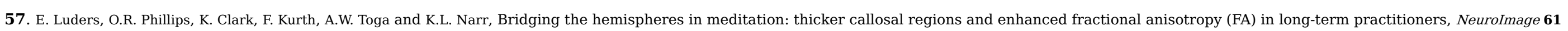
(1), 2012, 181-187, https://doi.org/10.1016/j.neuroimage.2012.02.026.

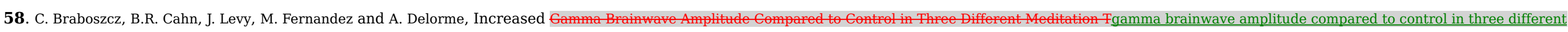
meditation traditions, PLoS One 12 (1), 2017, e0170647, https://doi.org/10.1371/journal.pone.0170647.

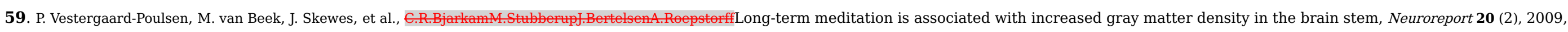
170-174, https://doi.org/10.1097/WNR.0b013e328320012a.

\section{Highlights}

- Yoga has positive effect on learning rate, speed and accuracy of a motor task

- Yoga improves sensory awareness and interoception, regulate autonomic input, increase parasympathetic activity and promote self-regulation,

- Yoga reduces the threat signal, increase pain tolerance, decrease pain unpleasantness and decrease the anxiety and distress associated with pain.

- A variety of brain areas are involved in these functions and specifically recruited during the practice of yoga:

- No study has yet specifically looked at the effects of yoga on motor performance on specific population!

\section{Queries and Answers}

Query: The author names have been tagged as given names and surnames (surnames are highlighted in teal color). Please confirm if they have been identified correctly. Answer: yes those are our surnames

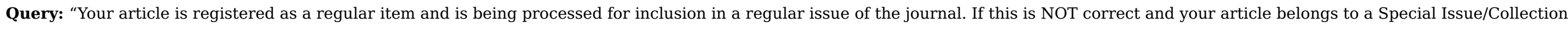
please contact s.gudiseva@elsevier.com immediately prior to returning your corrections.".

Answer: our article is a regular item

Query: Reference 'Eyre (2016)' is cited in the text but not provided in the reference list. Please provide it in the reference list or delete the citation from the text.

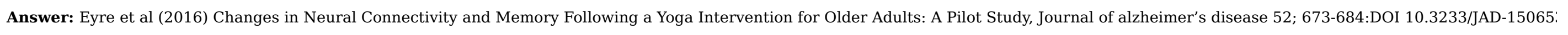

Query: Reference 'Green (2006)' is cited in the text but not provided in the reference list. Please provide it in the reference list or delete the citation from the text.

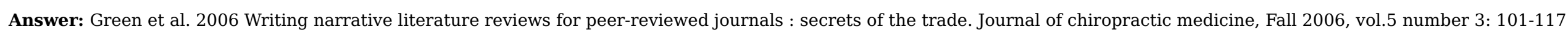

Query: Please check the citation of Ref. 41, and correct if necessary.

Answer: yes this is correct 
Query: Please check the hierarchy of the section headings, and correct if necessary.

Answer: looks good

Query: Please note that Table 5 was not cited in the text. Please check the citation, and correct if necessary.

Answer: This is our abbreviations. It does not have to be referred to as a table.

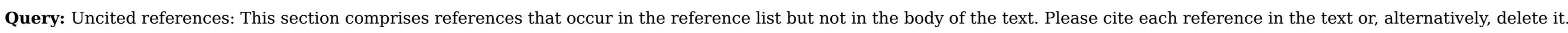
Answer: Please delete references that do not appear in the text.

Query: Reference 'Grant et al. (2009)' is cited in the text but not provided in the reference list. Please provide it in the reference list or delete the citation from the table.

Answer: here it is: Grant, J. A., \& Rainville, P. (2009). Pain sensitivity and analgesic effects of mindful states in Zen meditators: A cross-sectional study.

Psychoso- matic Medicine, 71, 106-114

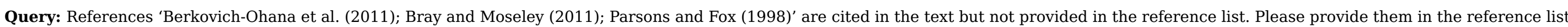
or delete the citation from the table.

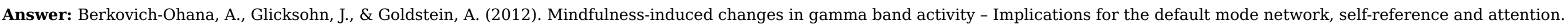
Clinical Neurophysiology, 123, 700-710. doi:0.1016/j.clinph.2011.07.048

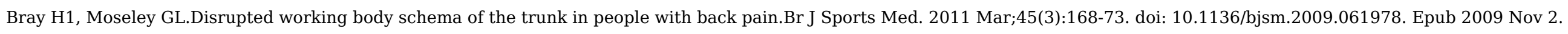

Parsons, L. M., \& Fox, P. T. (1998). The neural basis of implicit movements used in recognising hand shape. Cognitive Neuropsychology, 15(6-8), 583-615. 